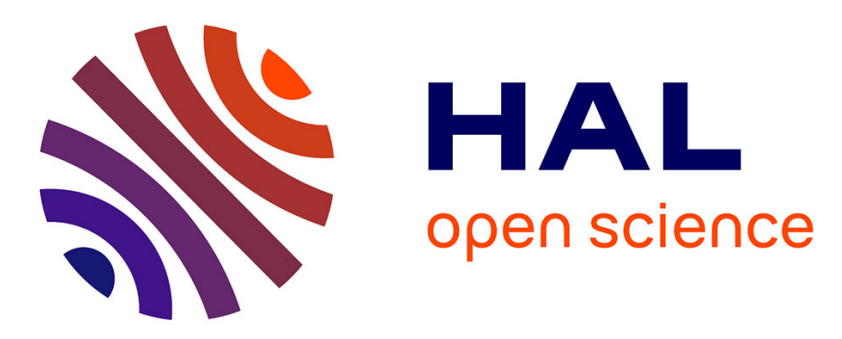

\title{
The ossicular chain of Cainotheriidae (Mammalia, Artiodactyla)
}

Alexandre Assemat, Mickaël Mourlam, Romain Weppe, Jacob Maugoust, Pierre-Olivier Antoine, Maeva Judith Orliac

\section{- To cite this version:}

Alexandre Assemat, Mickaël Mourlam, Romain Weppe, Jacob Maugoust, Pierre-Olivier Antoine, et al.. The ossicular chain of Cainotheriidae (Mammalia, Artiodactyla). Journal of Anatomy, 2020, 237 (2), pp.250-262. 10.1111/joa.13190 . hal-03057235

\section{HAL Id: hal-03057235 \\ https://hal.science/hal-03057235}

Submitted on 11 Dec 2020

HAL is a multi-disciplinary open access archive for the deposit and dissemination of scientific research documents, whether they are published or not. The documents may come from teaching and research institutions in France or abroad, or from public or private research centers.
L'archive ouverte pluridisciplinaire HAL, est destinée au dépôt et à la diffusion de documents scientifiques de niveau recherche, publiés ou non, émanant des établissements d'enseignement et de recherche français ou étrangers, des laboratoires publics ou privés. 
Short running page heading: Ossicular chain of Cainotheriidae

Title: The ossicular chain of Cainotheriidae (Mammalia, Artiodactyla)

Authors names: Assemat A. ${ }^{1}$, Mourlam M.J. ${ }^{1}$, Weppe R. ${ }^{1}$, Maugoust J. ${ }^{1}$, Antoine P.-O. ${ }^{1}$, Orliac M.J. ${ }^{1}$

Corresponding author: Mourlam M.J. (mickael.mourlam@ umontpellier.fr)

\title{
Authors affiliations:
}

1 - Institut des Sciences de l'Evolution, UMR 5554 (CNRS, IRD, EPHE), Université de Montpellier, Place Eugène Bataillon, 34095 Montpellier cedex 5

\begin{abstract}
:
This work describes an unparalleled sample of isolated fossil auditory ossicles of cainotheriid artiodactyls from the Paleogene karstic infillings of Dams (Tarn-et-Garonne, Quercy, France). This collection comprises a total of 18 mallei, 28 incudes and three stapedes. It allows the documentation of both intra- and interspecific variability of ossicular morphology within Cainotheriidae. We show that despite considerable intraspecific variability, the malleus, the incus, and the stapes appear to be taxonomically informative at the Cainotheriidae scale. This work further provides the first description of a reconstructed ossicular chain of a terrestrial Paleogene artiodactyl species, found in a basicranium of the late Oligocene cainotheriine Caenomeryx cf. procommunis (Pech Desse locality).
\end{abstract}

Key-Words: Morphometry, Malleus, Incus, Stapes, Paleogene, Quercy 


\section{Introduction}

The middle ear ossicles - the malleus, the incus, and the stapes - form a bony chain contained within the air-filled middle ear cavity. Their presence is a hallmark of Mammalia (e.g., Simpson, 1959; Luo et al. 2001). The three ossicles are the smallest bones of the mammalian skeleton and they play a fundamental role in hearing process. Indeed, the ossicular chain transmits the airborne sound waves from the tympanic membrane (at the interface between the outer and middle ear) to the fluid-filled cochlea of the inner ear, while performing an anatomical impedance match between this two media (e.g., Wever \& Lawrence, 1954; Dallos, 1973; Schubert, 1978; Killion \& Dallos, 1979; Peake \& Rosowski, 1991; Hemilä et al. 1995; Nummela \& Thewissen, 2008; Mason, 2016). Morphology of the ossicular chain and its specificity within different mammalian groups has been intensely studied for systematic purposes (e.g., Doran, 1878; Fleischer, 1973; Schmelzle et al. 2005; Wible \& Spaulding, 2012; Mason, 2013; Stoessel et al. 2016; Maier \& Ruf, 2016a, 2016b; Kerber \& Sánchez-Villagra, 2018; Loza et al. 2018), or functional aspects (e.g., Fleischer, 1978; Nummela, 1995; Nummela \& Sánchez-Villagra, 2006; Puria \& Steele, 2010). Most of these works deal with extant taxa, and, because of their fragility and small size, ossicles are rarely preserved - or at least retrieved - in the fossil records. Yet, when retrieved, they bring useful observations for the systematics or ecology of taxa, or both [e.g., systematic position of Pakicetidae (Thewissen \& Hussain, 1993) and hearing mechanisms in early cetaceans (Nummela et al. 2004; Nummela et al. 2007) among Artiodactyla]. Still, fossil ossicles are rarely preserved all three together, and almost never found in anatomical connection.

Here, we describe a broad sample of isolated ossicles of Cainotheriidae from Paleogene karstic infillings from Quercy (Tarn-et-Garonne, France). Cainotheriids are an extinct family of small artiodactyls (even-toed ungulates) documented in the fossil record between the late Eocene and the middle Miocene in Western Europe (Blondel, 2005). Because of their unique dental morphology, the phylogenetic position of Cainotheriidae within artiodactyls is still debated. They have been related to different European endemic families (Romer 1966; Webb \& Taylor, 1980; Gentry \& Hooker, 1988) without reaching a consensus, or to modern groups of artiodactyls such as ruminants (Geisler \& Uhen, 2005; O'Leary \& Gatesy, 2007; Lihoreau et al. 2015) or tylopods (Geisler \& Uhen, 2003; Geisler et al. 2007; Thewissen et al. 2007). The recent phylogenetic study of Weppe et al. (2019) retrieved Cainotheriidae closely related to the European endemic families Mixtotheriidae, Anoplotheriidae and Robiacinidae. 
Cainotheriidae are particularly abundant in karstic localities from Quercy, southwestern France. This family, which includes at least five genera within two sub-families ranges from rabbit-sized species to size of a small ruminant (Erfurt \& Métais, 2007; Theodor, 2010). Contrary to many European endemic ungulates which went extinct at the end of the Eocene (Sudre \& Legendre, 1992; Blondel, 2001), cainotheriids made it through the Eocene/Oligocene transition and they are one of the very few artiodactyl groups to diversify during Oligocene times (Blondel, 2005). The ossicles we describe here originate from two loci from the karstic network of Dams, discovered in 2016. This karstic network was emptied during the extensive phosphate exploitation that took place in Quercy during the late $19^{\text {th }}$ century. The network, however, still houses a great quantity of clay infillings including two channels that yielded a great quantity of cainotheriid remains, namely DAM1 and DAM3. These two infillings within Dams network bracket the Eocene-Oligocene transition (Weppe et al. 2019) and they document a period that corresponds to a major faunal turnover in Western Europe linked to climatic, geographic and oceanic circulation changes (Legendre, 1987; Berggren \& Prothero, 1992). Based on the unprecedented sample from Dams, including a total of 18 mallei, 28 incudes and three stapedes, and on an in-situ ossicular chain from Pech Desse (Quercy, France, late Oligocene), we discuss the intra- and interspecific variability of ossicle morphology within Cainotheriidae and describe for the first time a reconstructed ossicular chain for a Paleogene terrestrial artiodactyl species.

\section{Material and methods}

\section{Material}

Most of the specimens included in this analysis come from the Dams karstic network located near Caylus (Tarn-et-Garonne) in Quercy (SW France). All specimens studied are curated at the University of Montpellier (UM). The Dams material was collected after screenwashing of 40kg from DAM1 and 30kg from DAM3 in 2016. Raw fossil material was first concentrated by wet screening of the red clays collected in Dams locality, (0.7-mm mesh size), and then picked up with smooth tweezers, under a stereomicroscope. The material consists of 16 mallei, 16 incudes, and two stapedes from DAM1 (late Eocene, Mammalian Paleogene reference level 19 [MP19]; Weppe, 2018) and 12 incudes (among which two are in connection with the malleus head), and one stapes from DAM3 (early Oligocene, MP22; 
Weppe, 2018). The taxonomic identification of the isolated ossicles from Dams relies on a strong corpus of evidences: 1) the relative abundance of mammalian fossil remains; $90 \%$ of the remains (cranial, dental and postcranial) from DAM1 belong to the small cainotheriid artiodactyl Paroxacron valdense. Therefore, all the mallei and 16 incudes upon 18, that can be referred to the same morph, likely correspond, based on the relative abundance criterion, to Paroxacron valdense; 2) Artiodactyla hallmark; the incus presents a processus longum slightly smaller than the processus brevis which is a characteristic of Artiodactyla (Doran, 1878; Wilkie, 1936; Thewissen \& Hussain, 1993; Thewissen, 1994; Milinkovitch \& Thewissen, 1997); 3) incudo-mallear joint association; the association between the malleus and the incus, besides general size compatibility and match between the articular surfaces, is based on fused incudo-mallear complexes found in DAM3.

Based on these criterions, the ossicles from DAM1 are all assigned to Paroxacron valdense, the only cainotheriid species retrieved in this channel (Weppe, 2018). In contrast, five different cainotheriid species co-occur in DAM3, making specific attribution of the isolated ossicles impossible (in the current state of our knowledge). A list of the included material is provided in supplementary information Table S1. Other incudes of similar size have been found in both levels (DAM1 and DAM3), but they are not included in this study due to their markedly different morphology that would point to rodents or chiropterans instead of artiodactyls. In addition to the ossicles from Dams localities, we reconstruct in this work the in-situ location of the cainotheriid ossicular chain based on a basicranium (UM PDS 3353) from the late Oligocene locality of Pech Desse (MP28, Quercy; Hugueney, 1997) that preserves the ossicles trapped in the middle ear cavity. Two cainotheriine species are retrieved in Pech Desse, namely Plesiomeryx cf. cadurcensis and Caenomeryx cf. procommunis (Remy et al. 1987). Based on the overall larger dimensions of the specimen, it is here referred to as Caenomeryx cf. procommunis.

\section{Micro CT scanning and virtual reconstruction}

The ossicles were scanned, using the high-resolution micro CT-scanner EasyTom of the technical facility of the Montpellier Rio Imaging platform, at a high voltage (150 kV) using a copper filter and small sample holders ( 2 and $4 \mathrm{~cm}$ diameters), allowing to be close to the $\mathrm{X}$ ray source and therefore, to reach a voxel size of $11.89 \mu \mathrm{m}$ for isolated specimens, and 23.81 $\mu \mathrm{m}$ for the partial cranium UM PDS 3353. They were reconstructed virtually in 3D using the 
threshold tool of Avizo 9.5 (VSG-FEI) software. The specimens partly encrusted with matrix were cleaned using the manual segmentation tool of the same software. The virtual reconstruction of the in-situ location of the ossicular chain of cainotheriid from Pech Desse was realized using the freeware MorphoDig (Lebrun, 2018). Anatomical terminology used in this study mainly follows that of Wible and Spaulding (2012); orientations are based on the reconstruction of the in-situ ossicle chain of the cranium UM PDS 3353.

\section{Geometric morphometric analysis}

Nine mallei and nine incudes from DAM1 and five incudes from DAM3 are included in the geometric morphometric analyses, other specimens being discarded due to their fragmentary condition. In addition, the incus and malleus from the Pech Desse specimen were also added to the analyses. Only three stapedes were unearthed in Dams localities, which does not allow a proper discussion of the morphometrical variability of this ossicle. To quantify the malleus and incus shape variations, we digitized a set of 3D landmarks using MorphoDig software (MorphoDig 0.8) (Fig. 1). Nine landmarks were placed on the malleus including five on the articular area. The first one was placed at the highest point of the curve along the medial margin of the articular area. The second one occupies the same position on the distal margin of the articular area. The third landmark is located at the center of the ridge of the articular area. The fourth and the fifth landmarks were placed on the deepest points along the dorsal and ventral borders of the articular facet, respectively. The sixth landmark was placed at the extremity of the muscular process and the seventh one is located on the notch between the muscular process and the manubrium. The eighth is positioned at the deepest point of the angulation formed by the neck of the malleus with the manubrium. The last one was placed at the extremity of the anterior process. On the incus, we positioned nine landmarks, including five on the articular area. The first one was placed on the deepest part on the lateral border of the articular area and the second one at an equivalent location on the medial border. Landmarks three and four were placed on the most salient points of the articular surface i.e., on the dorsal and ventral edge, respectively. The fifth landmark is located at the central position of the bulge formed by the intersection of the two articular facets. Landmarks six and seven are positioned on the incudal body. The sixth one is at the middle of the swelling along the upper border of the incudal body and the seventh was placed at the middle of the curve joining the short and the long process posteroventrally. The eighth landmark was placed internally to the long process where it becomes thinner, while the ninth one was positioned at 
the extremity of the short process. The treatment of the raw dataset was performed using $\mathrm{R}$ software version 3.4.4 (R Core Team, 2018). All 10 replicates were scaled to unit centroid size (i.e. "the square root of the sum of squared distances from each landmark to the centroid of the configuration" Claude, 2008:139), translated, rotated, and superimposed through the Generalized partial Procrustes Analysis (pGPA) following Claude (2008, 2013; see also Bookstein, 1990; Rohlf, 1990; Dryden \& Mardia, 1998). Then, to apprehend the shape variability of the malleus and incus, we performed a Principal Component Analysis (PCA; Pearson type) on the Procrustes coordinates (resulting from the pGPA). Error measurement follows Yezerinac et al. (1992; see also Claude et al. 2003; Claude, 2008: 65-66, 2013). Data and script are available in supplementary material dataset 1.

\section{Data availability statement}

All specimens studied are curated at the University of Montpellier (UM) and can be freely consulted upon request. The 3D models of the middle ear reconstruction of Caenomeryx cf. procommunis is available in open access on MorphoMuseuM (https://morphomuseum.com/; Assemat, in press). The scripts used to perform the morphometric analyses are provided in supplementary information.

\section{Description}

\section{Malleus (Figs. 2-3)}

The description of the cainotheriid malleus (Fig. 2) primarily relies on material from the DAM1 locality as DAM3 only yielded malleus articular surfaces fossilized in anatomical connection with the incus. The malleus is the most lateral part of the ossicular chain. In life, it contacts the tympanic membrane by a long, flat-shaped manubrium and a short and angular lateral process. The malleo-incudal complex is unfused for all documented specimens from DAM1. The globose head of the malleus bears the articular surface for the incus. The latter is divided into two facets separate by a deep and wide groove; the superior articular facet for the incus lies in the dorsal aspect, while the inferior articular facet, of about the same size, lies at ca. $35^{\circ}$ angle to it (Fig. 2A). The general shape of the articular surface is saddle-like and is asymmetrical related to the fact that the groove is wider and shallower on the dorsomedial 
part. On the anterior surface, the head comes to a small, rounded point that we identify as a blunt capitular spine (Wible \& Spaulding, 2012). A thin and sharp bony crest joins the basis of this spine to the anterior process, the outer lamella (Henson, 1961). Lateral to the capitular spine, the surface of the head is carved by a small pit. The neck of the malleus is relatively straight and it forms with the head an obtuse angle which confers to the malleus a general sigmoidal shape. It is relatively broad and lines the osseous lamina on the posteromedial edge. The osseous lamina consists of a particularly thin portion of bone bearing a depression on the lateroventral aspect of the malleus (Fig. 2D); there is no clear demarcation with the basis of the manubrium. The specimens of our sample seem to display a short blunt anterior process, also known as processus gracilis, or prearticular, and mentioned in living artiodactyls (Wible \& Spaulding, 2012; Maier \& Ruf, 2016b). It might have displayed a much thinner terminal part but it would have been broken away during the fossilization process and left no trace. As illustrated for carnivorans by Wible \& Spaulding (2012), the base of the manubrium corresponds to the confluence of the neck, lateral process, and ventral margin of the osseous lamina. The manubrium is long with a flat and thin tympanic surface. The latter is much wider than the lateral edge which bears a ridge becoming narrower at the manubrium's extremity. Unfortunately, the manubrium is partly broken on all isolated specimens. It displays a welldeveloped lateral process at the posterior margin of its base. The medial margin of the bone bears a strong and conical muscular process forming a $40^{\circ}$ angle with the manubrium. The course of the chorda tympani nerve is marked on the ventral aspect of the muscular process.

Comparison. The small and flat head of the malleus of the cainotheriids from Dams is closer in proportion and shape to Ruminantia as illustrated in Capreolus and Giraffa by Fleischer (1973) than to Sus, Hippopotamus, and Camelus. Like ruminants, they also display a long neck and a wide osseous lamina. In suids, hippos, and camelids, the neck is shorter and the osseous lamina remains smaller and closely appressed to the head. Compared to hippos and suids, the cainotheriid malleus also displays a shorter but stockier muscular process which is closer to the manubrium. The muscular process global shape in cainotheriids is relatively similar to that of some living ruminants (e.g. Bos taurus, Ovis aries, and Cervus elaphus).

Inter- and intraspecific variation. The morphology of the 16 mallei from DAM1 shows a noticeable variability mainly affecting the length of the malleus neck, the angulation of the lateral process, the shape, depth and orientation of the articular surface, and also the location, length and shape of the muscular process (Fig. 2G-H; Fig. S1A-H). In addition, in comparison 
with the specimens from DAM1, the malleus from Pech Desse displays a different morphology of its articular surface. In order to quantify this inter- and intraspecific shape variation of the malleus, we performed two pGPAs, one with all available mallei (interspecific analysis; see Material and methods) and one without the Pech Desse specimen (intraspecific analysis). Due to small breakages on the latter specimen, interspecific shape variation has been quantified by taking into account only the first seven landmarks. For the interspecific analysis, measurement error is $6.92 \%$ for centroid size and $16.88 \%$ for shape. Inter-specimen size and shape variations are stronger than the intra-specimen ones (specimen factor is significant in both ANOVA $(\mathrm{F}=135.4 ; \mathrm{p}<0.001)$ and Procrustes ANOVA $(\mathrm{F}=50.23 ; \mathrm{p}=$ 0.001); see also Claude, 2013). The Fig. 3A presents the projection of the specimens on the first factorial plane. PC1 (52.96\% of the variance) clearly separates the Pech Desse specimen from the other mallei and highlights deep morphological difference in term of shape and orientation of the articular facets of the two species. The mallei from DAM1 present intraspecific variation mainly on PC2 (19.72\% of the variance) that corresponds with small size variation of the articular surface and slight variations of orientation of the body of the malleus in regards to its head. More precisely, projection of individuals on the first factorial plane (48.82\% of the variance) of the intraspecific analysis (Fig. 3D; where measurement error for centroid size is $5.08 \%$ with specimen factor significant $(F=187.7$; $<<0.001)$ and measurement error for shape is $23.41 \%$ with specimen factor significant $(\mathrm{F}=33.72 ; \mathrm{p}=$ 0.001)), underlines these variations. Indeed specimens from DAM1 are distributed more or less randomly along the first two PCs that both stand for size variation of the articular surface. Furthermore, PC1 also presents variation of orientation of the anterior process and PC2 highlights variation of orientation of the muscular process and of the main body in regards to the malleus head. This disparity of orientation of the malleus body can also be observed directly by superimposing all the mallei while keeping the same position for the articular surface (Figs. 2G-H, 3E-F).

\section{Incus (Figs. 4-5)}

The incus is the middle ossicle joining the malleus and the stapes. It is conical and stocky in shape (Fig. 4 A-B). The wide articular area of the incudomallear joint is composed of two asymmetrical facets. It displays the same asymmetry as previously described for the malleus. A salient edge, of different size depending on the specimen, separates the articular surface from the incudal body (Fig. 4D). The dorsal aspect of the incus is variably convex, 
from nearly flat to strongly domed. The cainotheriid incus displays two processes of similar length, set apart by a wide angle; the processus brevis and the processus longum. The processus brevis prolongs posteriorly the incudal body. The processus longum, which connects the stapes by the lenticular apophysis, is located on the ventral edge of the incus, posterior to the articular surface. The distal extremity of the processus longum of all incudes of our sample is broken so that no lenticular apophysis is documented. A groove starts at the base of the processus longum and runs all along of it. The separation between the two processes is strengthened by the length of the body of the incus. The processus brevis of the cainotheriid incus displays a thinning at its extremity while the processus longum is thicker. The extremity of the processus longum ends in a small spike that corresponds to the attachment of the broken lenticular apophysis.

Comparison. The cainotheriid incus is morphologically similar to that of other artiodactyls with two processes of about the same length, whereas in most other mammals, the processus longum is longer than the processus brevis (Doran, 1878). Cainotheriid incudes from Dams differ from those of Camelus in having further apart processes, separated by a wider angle. The articular area of cainotheriid incudes appears to be shallower than in camels, but deeper than in bovines (Doran, 1878, Pl. 61). The body of studied incudes is close in shape to that of Sus scrofa. It is more massive in the hippos and the llama which also display a more cylindrical shape. Ruminants display a wide range of incudal body morphologies (Doran, 1878; Wilkie, 1925; Wilkie, 1936). The scarcity of illustrations available in the literature prevents a broader comparison among artiodactyls.

Inter- and intraspecific variation. The incudes from DAM1 and DAM3 show a noticeable variability of the depth of the articular facet and of the angulation between the processus brevis and the processus longum. They also display a variation of their dorsal part bulge (Fig. 4F, Fig. 5A-B, Fig. S1I-M). In order to quantify inter- and intraspecific shape variations, we performed a pGPA on a dataset of nine three-dimensional landmarks (Fig. 1B; see Material and methods section, Geometric morphometric analysis) for a sample of 15 incudes from DAM1, DAM3 and Pech Desse. For this analysis, measurement error is $3.14 \%$ for centroid size, $18.82 \%$ for shape and inter-specimen size $(\mathrm{F}=309.4 ; p<0.001)$ and shape $(\mathrm{F}=44.13$; $p=0.001)$ variations are significantly stronger than the intra-specimen ones. The two first PCs explain $56.32 \%$ of the variance (Fig. 5A). The main shape variation contributions of PC1 (39.12\% of the variance) correspond with an elongation of the processus brevis, correlated 
with a smoother and thinner dorsal bulge toward the positive values (Fig. 5 B). PC1 also displays shape and orientation variations of the articular facets following the same trends observed for the interspecific variation of the malleus (see above). PC2 (17.20\% of the variance) mainly highlights the variation of angulation between the two processes (Fig. $5 \mathrm{C}$ ). The projection of the specimens on the first factorial plane results in two slightly overlapping groups corresponding to DAM1 and DAM3 localities. DAM3's morphospace, with a surface that covers $41 \%$ of the whole sample's morphospace, is nearly five times more expanded than that of DAM1 (that covers 8.6\%). Only one specimen from DAM3 lies within DAM1's morphospace. Incudes from DAM1 present intraspecific variability along PC1 and PC2, highlighting mostly variation of the angulation between the two processes and also, small size variation of the articular surface. PC1 also clearly isolates the Pech Desse specimen from the incudes retrieved in Dams. Indeed, in terms of Mahalanobis distance on the first five PCs, the specimens from DAM3 are always retrieved at least twice as far from the Pech Desse specimen as from the centroid of DAM1 (see Tab. S2).

\section{Stapes (Fig. 6)}

The stapes is the most proximal element of the ossicular chain. Located medioposteriorly relative to the other ossicles, it is composed of a head, two crura (anterior and posterior), and a footplate. Regarding its connectivity, in life, the head articulates with the lenticular apophysis of the incus while the footplate sits on the fenestra vestibuli, retained by the annular ligament. The isolated nature of the stapes and the high resolution of $\mu \mathrm{CT}$-scan acquisition performed here permit us to describe the structure of this ossicle in cainotheriids in more detail than was possible for Orliac and Billet (2016).

The stapedes from DAM1 present a global trapezoidal shape with two long crura separated by a wide foramen intercrurale (Fig. 6 A-B). The latter has the same size on the medial and lateral surface and it extends from the head to the large footplate. The two DAM1 stapedes are very similar in terms of size and shape of the foramen intercrurale. Their footplate are roughly oval in shape and concavo-convex, with a prominent umbo. In the specimen from DAM3, the footplate is bean-shaped (Fig. $6 \mathrm{C} v s \mathrm{M}$ ). In the DAM1 stapes, the rim is thick along its whole length, unlike that of DAM3, the rim of which is thicker posteriorly and much thinner anteriorly. On the stapes head, the articular facet for the lenticular apophysis of the processus longum is narrow and oval, slightly convex 
anteroposteriorly and slightly concave mediolaterally (Fig. 6 A, D). The processus muscularis stapedis, located on the top of the posterior crus, appears to be larger in the DAM1 stapedes than in that from DAM3. The general shape of the bone is asymmetrical in specimens from both DAM1 and DAM3, with the anterior crus longer and slenderer than the posterior one. The posterior crus is slightly straighter in DAM1 stapedes.

Comparisons. The morphology of the cainotheriid stapedes from Dams differs from those of the cow and llama which present a more rectangular general shape in lateral view, due to more symmetrical crura and smaller footplates (Doran, 1878; Fleisher, 1973; Costeur et al. 2016). The cainotheriid stapedes from Dams, like in hippopotamids, display a wide foramen intercrurale extending to footplate; hippopotamids however differ in having a smaller head and a more elliptic (i.e. not asymmetrical) footplate (Fleisher, 1973, fig. 41; Orliac \& Billet, 2016, fig. 2C-D). Asymmetrical crura as observed in cainotheriids are also observed in camelids (Camelus bactrianus; Bai et al. 2009), suoids (Tayassu tajacu and Microstonyx erymanthius; Orliac \& Billet, 2016) and ruminants (e.g. Giraffa camelopardalis; Doran, 1878).

\section{Reconstruction of the ossicular chain of the cainotheriin Caenomeryx filholi}

The marked intra-specific variability of ossicle shape makes it difficult to reconstruct an articulated ossicular chain based on composite material. We therefore performed a reconstruction of the ossicular chain based on in-situ ossicles preserved in the middle ear cavity of the basicranium UM PDS 3353 from Pech Desse (MP 28, Quercy). The malleus and the stapes were preserved within the left bullar space, while the right side preserved the malleus and the incus. Due to postmortem soft-tissue decay, the ossicles were no longer in connection. A complete middle ear was therefore virtually reconstructed using the left bulla, petrosal and incus and mirror-3D models of the right malleus and stapes. Based on the relative position of the tympanic ring of the bulla and of the fenestra vestibuli of the petrosal, we propose a reconstruction of the three-dimensional orientation of the ossicles within the middle ear cavity (Fig. 7A-D). The malleus is positioned so that it closes anterodorsally the tympanic ring with its anterior process, and that the manubrium contacts the tympanic membrane with its flat part oriented ventrally. Unfortunately, the anterior process of the malleus is broken away on both sides, and the connectivity with the bulla could not be fully assessed. The incus contacts the malleus via the articular area, while it connects the petrosal by soft tissues fixed 
on the processus brevis. The contact with the stapes is realized by the lenticular apophysis, a very fragile structure that is not preserved here. Nevertheless, according to the location of the fenestra vestibuli (determining the position of the stapes within the middle ear cavity), this process seems to have been orthogonal to the processus longum of the incus. The 3D model of the middle ear reconstruction is available on MorphoMuseuM (Assemat, in press).

Compared to the mallei from DAM1, the articular surface of the malleus from Pech Desse presents a wider angle between the superior and inferior articular facets (nearly $90^{\circ}$ for Pech Desse). In addition, the shape of their articular surfaces are clearly distinct; while the articular surface of the mallei of DAM1 (in posterior view) clearly disrupt from the neck of the malleus with a subrectangular shape that extends ventrodorsally, the head of the malleus of Pech Desse is much slender ventrodorsally and somehow extends continuously the neck of the malleus medially (Fig. 2A-B vs Fig. 7I; see also Fig. 3A-C). The orientation of the muscular process is also more medial. The malleus is generally more gracile in the specimen from Pech Desse. It preserves the delicate structure of the manubrium's extremity which is spatulated (Fig. 7C-D), for the DAM1 material, it is difficult to assess if the manubrium is not spatulated or if this feature was broken away on specimens. The shape of the incus from Pech Dess reflects the differences observed at the level of the malleus articular surface. The stapes from Pech Desse (Fig. 7M-P) also exhibits a quite different morphology from that of DAM1, with a general profile slenderer anteroposteriorly, a smaller head (might be due to in situ partial preservation), slight differences in crura width and orientation, and footplate outlines that are oval instead of being bean-shaped. However, the morphology of the stapedial footplate is very similar, being elongated, concavo-convex in dorsal view, and bearing a wide stapedial footplate rim (Fig. 7M-P). The observation of the contact between the petrosal and the bulla (Fig. 7Q) using $\mu$ CT-scan data have not permitted us to confirm the presence of the processus internus praearticularis (pipa; Maier \& Ruf, 2016b), not visible in intracranial view between the tegmen tympani and the basisphenoid bone because of tight contact between the two structures.

\section{Discussion}

Inter- and intraspecific variability of the shape of the ossicles has been described for a few group of mammals such as the African mole-rats (Bathyergidae, Lange et al. 2007), the hominoid primates (Stoessel et al. 2016) and the golden moles (Chrysochloridae, Mason et al. 
2018). The sample from DAM1 composed of 16 mallei and 16 incudes, all referred to Paroxacron valdense, allows the consideration of intraspecific variability of these ossicles in this small extinct artiodactyl. The malleus shows a wide shape range; variations mainly affect the size of the articular facet and the rotation of malleus head relative to the body (Fig. 2 G$\mathrm{H})$. This considerable variability of the shape might result in non-negligible variations in the orientation of the ossicle chain in the auditory area or, in turn, in a similar variation range at the incus level. Indeed, just as for the malleus, the incudes from DAM1, also all referred to Paroxacron valdense, show a remarkable variability of shape (Fig. 4E-F; Fig. 5), mostly concerning the length of the processus brevis, the angle between the two processes, the dorsal bulging of the body, and the width of the articular facet.

Despite relatively significant shape variation, the morphospace of the incudes specimens from DAM1 - representing one single species - is smaller than that of those from DAM3, and rather well separated from it, except for one DAM3 specimen that lies within DAM1 morphospace. This individual from DAM3 could be a representative of the genus Paroxacron and could either document the species Paroxacron bergeri or Paroxacron sp. retrieved in DAM3 (Weppe, 2018). Indeed, the genus Paroxacron crosses the Eocene/Oligocene transition and is found both in DAM1 (with the single oxacronine cainotheriid species Paroxacron valdense) and DAM3 fossiliferous levels. The larger morphospace covered by the specimens from DAM3 compared to DAM1 could be explained by the co-occurrence in DAM3 of three different cainotheriid genera (Oxacroninae: Paroxacron; Cainotheriinae: Plesiomeryx and Caenomeryx), comprising five different species. The morphology of the younger ossicles from Pech Desse, assigned to Caenomeryx cf. procommunis, is also markedly different from those described from DAM1 and DAM3, confirming the potential systematic and phylogenetic interest of ossicular morphology, as shown by the wide array of morphologies observed within and between higher rank mammal groups (e.g., Doran, 1878; Fleischer, 1973; Nummela, 1995; Schmelzle et al. 2005; Mason, 2013; Solntseva, 2013). The morphology of the stapes has, for example, been proposed as a hallmark for major divisions among Placentalia (Novacek \& Wyss, 1986). The variation of shape observed among cainotheriid incudes between DAM1 and DAM3 supports the potential interest of ossicles at the generic level. Yet, establishing a morphotype reference based on ossicles for each cainotheriid genus seems most unlikely given the usual scarcity of these smallest bones among the fossil material collected in localities. At a wider scale, ossicles are likely to provide interesting signal at the Artiodactyla level and documentation of the morphology of the cainotheriid ossicle chain could be of interest to address the phylogenetic 
relationships of this extinct family. Actually, cainotheriids have been proposed to be closely related to tylopods (e.g., Gentry \& Hooker, 1988; Thewissen et al. 2007), or closer to ruminants (e.g., Geisler \& Uhen, 2005; O’Leary \& Gatesy, 2007). Recent results based on dental evidence placed them together with Anoplotheriidae and Mixtotheriidae, close to Ruminantia (Weppe, 2018). One stapes has been described for Anoplotheriidae (Diplobune minor; Orliac et al. 2017, fig. 3); it is morphologically very close to that described here for Paroxacron valdense, with asymmetrical crura, a large slender head, a wide foramen intercrurale, and a somewhat convex footplate. However, the general morphological signal carried by the ossicular chain is difficult to interpret at the Artiodactyla level yet, because modern groups also display a wide range of morphologies and specializations. The morphology of the malleus of Dams cainotheriids is close in proportion and shape to that of Ruminantia with a long neck, a wide osseous lamina, and a similar global shape of the muscular process. Compared to camelids and hippos, the manubrium of Caenomeryx is much more spatulated and shows a morphology close to rodents (e.g., Rattus Microtus, Fleischer 1973:fig.29, 31), carnivorans (e.g. Mustela, Fleischer 1973:fig.53) or primates (e.g., Galago, Macaca, Fleischer 1973:fig.18-19); the spatulated aspect strongly recalls that of golden moles (Willi et al., 2006). The meaning of spatulated manubrium in terms of sound transmission remains unclear as it is found in a wide array of mammalian species.

The cainotheriid incus brings little information and is morphologically similar to that of other artiodactyls with two processes of about the same length (Doran, 1878). Finally, the stapedial morphology seems to be closer to that of Anoplotheriidae than to any modern representatives of Artiodactyla illustrated in the literature. However, knowledge of early members of Ruminantia and Camelidae is necessary before a proper discussion is engaged on morphological proximity of Cainotheriidae with one modern group or the other.

The present cainotheriid sample provides a very first glimpse into Paleogene artiodactyl ossicle evolution and variability. Compared to the ossicles from DAM1 (dated at ca. $35 \mathrm{Ma}$ ), and DAM3 (ca. $32 \mathrm{Ma}$ ), the in-situ ossicular chain from Pech Desse (ca. $25 \mathrm{Ma}$ ) exhibits a quite different morphology, with more gracile elements. These morphological changes could echo a shift in cainotheriid ecological habits between the late Eocene and the late Oligocene. This shift may relate with deep environmental changes, such as the opening of the vegetation cover that occurred after the Grande Coupure in Western Europe (Collinson, 1992; Cavagnetto \& Anadón, 1996). However, documentation of the ossicular morphology of other Oligocene-Miocene cainotheriid genera (i.e., Plesiomeryx and Cainotherium) is necessary to 
properly address this question in the light of the phylogenetical signal, as revealed by craniodental morphology.

\section{Conclusions}

The unprecedented fossil ossicles sample from the karstic network of Dams, including a total of 18 mallei, 28 incudes and three stapedes, allows the documentation of intra- and interspecific variability of auditory ossicle morphology within Cainotheriidae. This descriptive work constitutes the first description of a reconstructed ossicular chain of a terrestrial Paleogene artiodactyl species. Despite considerable intraspecific variability, the malleus, the incus, and the stapes appear to be taxonomically informative at the Cainotheriidae scale. This highlights the interest of picking these tiny bones ( 1-2 mm long) when sorting out the sediments. Internal investigation of fossils by $\mu \mathrm{CT}$-scan imaging will certainly also allow for completing our knowledge of Paleogene artiodactyl ossicles, thereby widening our observations and conclusions, notably from a phylogenetic perspective.

\section{Acknowledgements}

We are especially grateful to Thierry Pélissié and Gilles Escarguel who organized the field campaign in Dams (since 2016) and who are in charge of field excavation and prospection in the Phosphorites of Quercy; we are also thankful to all the team of the Cloup d'Aural and to the Quercy research team (C. Blondel, PALEVOPRIM, Poitiers; M. Godinot, MNHN, Paris; S. Couette, EPHE, Dijon; Margot Bernardi, EPHE, Dijon; M. Vianey-Liaud, ISEM, Montpellier; Christian Bousquet, Cloup d'Aural) for their work in the field. Many thanks to M. Longuet for her help with sorting out the ossicles of DAM1. Finally, we are very grateful to M.J. Mason, S. Nummela, and L. Costeur for their fruitful comments and suggestion that helped us improving substantially this manuscript. This work was financially supported by the ANR program DEADENDER (ANR-18-CE02-0003-01) - PI M.J. Orliac. This is ISEM publication $n^{\circ} 2020-024$.

\section{Author contributions}

A. Assemat performed the morphological study, the statistical analyses, and wrote the paper. 
M. J. Mourlam supervised the statistical analyses and corrected different versions of the manuscript.
R. Weppe and J. Maugoust collected the material in the field, sorted out the specimens, and launched morphological analysis.

P.-O. Antoine collected the material in the field, supervised the field training and sediment screenwashing, and corrected the manuscript.

M. J. Orliac designed research, sorted out the material, prepared the figures, and wrote the manuscript.

\section{Bibliography}

Assemat A, Orliac M.J. (in press) 3D models related to the publication: The ossicular chain of Cainotheriidae (Artiodactyla, Mammalia). MorphoMuseuM

Bai ZT, Wang HJ, Yuan GQ, Ye WL, He JB, Wang JL (2009). A functional anatomy of the external and middle ear of the bactrian camel (Camelus bactrianus). J Camel Prac Res 16(1), 115-120.

Berggren WA, Prothero DR (1992) Eocene-Oligocene climatic and biotic evolution: an overview. In: Eocene-Oligocene climatic and biotic evolution, pp. 1-28. Oxford: Princeton University Press.

Blondel C (2001) The Eocene-Oligocene ungulates from Western Europe and their environment. Palaeogeogr Palaeoclimatol Palaeoecol 168(1-2), 125-139.

Blondel C (2005) New data on the Cainotheriidae (Mammalia, Artiodactyla) from the early Oligocene of south-western France. Zool J Linn Soc 144(2), 145-166.

Bookstein FL (1990) Introduction to methods for landmark data. In: Rohlf FJ, Bookstein FL (Eds.) Proceedings of the Michigan Morphometric Workshop, pp. 215-226. University of Michigan Museum of Zoology Special Publication 2

Cavagnetto C, Anadón P (1996) Preliminary palynological data on floristic and climatic changes during the Middle Eocene-Early Oligocene of the eastern Ebro Basin, northeast Spain. Rev Palaeobot Palynol 92(3-4), 281-305.

Claude J (2008) Morphometrics with R. Springer Science \& Business Media.

Claude J (2013) Log-shape ratios, Procrustes superimposition, elliptic Fourier analysis: three worked examples in R. Hystrix It. J. Mamm 24(1), 94-102. 
Claude J, Paradis E, Tong H, Auffray J-C (2003). A geometric morphometric assessment of the effects of environment and cladogenesis on the evolution of the turtle shell. Biol. J. Linn. Soc. Lond. 79, 485-501.

Collinson ME (1992) Vegetational and floristic changes around the Eocene/Oligocene boundary in Western and Central Europe. In: Eocene-Oligocene climatic and biotic evolution, pp. 437-450. Oxford: Princeton University Press.

Costeur L, Mennecart B, Müller B, Schulz G (2016) Middle ear bones of a mid-gestation ruminant foetus extracted from X-ray computed tomography. Proc SPIE - Inter Soc Opt Engin. DOI: 10.1117/12.2238119.

Dallos P (1973) The Auditory Periphery: Biophysics and Physiology. New York: Academic Press.

Doran AHG (1878) Morphology of the mammalian ossicula auditus. Trans Linn Soc Lond Zool 1, 371-497.

Dryden IL, Mardia KV (1998) Statistical Shape Analysis. Wiley, Chichester.

Erfurt J, Métais G (2007) Endemic European Paleogene Artiodactyls: Cebochoeridae, Choeropotamidae, Mixtotheriidae, Cainotheriidae, Anoplotheriidae, Xiphodontidae, and Amphimerycidae. In: Prothero DR, Foss SE (Eds.) The Evolution of Artiodactyls, pp. 5984. Baltimore, Maryland: The Johns Hopkins University Press.

Fleischer G (1973) Studien am Skelett des Gehörorgans der Säugetiere, einschließlich des Menschen. Säugetierkund Mitteil 21, 131-239.

Fleischer G (1978) Evolutionary principles of the mammalian middle ear. Adv Anat Embryol Cel 55, 1-70.

Geisler JH, Theodor JM, Uhen MD, Foss SE (2007) Phylogenetic Relationships of Cetaceans to Terrestrial Artiodactyls. In: Prothero DR, Foss SE (Eds.) The Evolution of Artiodactyls, pp. 19-31. Baltimore, Maryland: The Johns Hopkins University Press.

Geisler JH, Uhen MD (2003) Morphological support for a close relationship between hippos and whales. J Vertebr Paleontol 23, 991-996.

Geisler JH, Uhen MD (2005) Phylogenetic relationships of extinct cetartiodactyls: results of simultaneous analyses of molecular, morphological, and stratigraphic data. J Mammal Evol 12, 145-160.

Gentry AW, Hooker JJ (1988) The phylogeny of the Artiodactyla. In: The phylogeny and classification of the tetrapods: Mammals, pp. 235-272. Oxford: Clarendon Press. 
Hemilä S, Nummela S, Reuter T (1995) What middle ear parameters tell about impedance matching and high-frequency hearing. Hear Res 85, 31-44.

Henson OW Jr (1961) Some morphological and functional aspects of certain structures of the middle ear in bats and insectivores. Univ. Kans. Sci. Bull. 42(3), 151-255.

Hugueney M (1997) Biochronologie mammalienne dans le Paléogène et le Miocène inférieur du Centre de la France : synthèse réactualisée. In: Actes du Congrès BiochroM'97, pp. 417-430. Montpellier: Mémoires et Travaux de l'Institut de Montpellier de l'Ecole Pratique des Hautes Etudes 21.

Kerber L, Sánchez-Villagra MR (2018) Morphology of the Middle Ear Ossicles in the Rodent Perimys (Neoepiblemidae) and a Comprehensive Anatomical and Morphometric Study of the Phylogenetic Transformations of these Structures in Caviomorphs. J Mammal Evol 116. doi.org/10.1007/s10914-017-9422-9.

Killion MC, Dallos P (1979). Impedance matching by the combined effects of the outer and middle ear. J Acoust Soc Am 66, 599-602.

Lebrun R (2018) MorphoDig, an open-source 3D freeware ded- MorphoDig, an open-source 3D freeware ded- icated to biology. 5th International Paleontological Congress, Paris.

Legendre S (1987) Les communautés de mammifères d'Europe occidentale de I'Eocène supérieur et Oligocène: structures et milieux. Münchr geowiss Abh 10(A), 310-312.

Lihoreau F, Boisserie J-R, Manthi FK, Ducrocq S (2015) Hippos stem from the longest sequence of terrestrial cetartiodactyl evolution in Africa. Nat Commun 6. doi: 10.1038/ncomms7264.

Loza CM, Reutimann O, Sánchez-Villagra MR, Carlini AA, Aguirre-Fernández G (2018) Evolutionary transformations of the malleus in pinnipeds, with emphasis on Southern Hemisphere taxa. Contrib Zool 87(2), 75-85.

Luo ZX, Crompton AW, Sun AL (2001) A new mammaliaform from the early Jurassic and evolution of mammalian characteristics. Science 292(5521), 1535-1540.

Maier W, Ruf I (2016a) Evolution of the mammalian middle ear: a historical review. J Anat $228,270-283$.

Maier W, Ruf I (2016b) The anterior process of the malleus in Cetartiodactyla. J Anat 228, $313-323$.

Mason MJ (2013) Of mice, moles and guinea-pigs: functional morphology of the middle ear in living mammals. Hear Res 301, 4-18.

Mason MJ (2016) Structure and function of the mammalian middle ear. II: Inferring function from structure. J Anat 228, 300-312. 
Milinkovitch MC, Thewissen JGM (1997) Evolutionary biology. Even-toed fingerprints on whale ancestry. Nature 388, 622-624.

Novacek MJ, Wyss A (1986) Origin and transformation of the mammalian stapes. Rocky Mount Geol 24, 35-53.

Nummela S (1995) Scaling of the mammalian middle ear. Hear Res 85(1), 18-30.

Nummela S, Sánchez- Villagra MR (2006) Scaling of the marsupial middle ear and its functional significance. J Zool 270(2), 256-267.

Nummela S, Thewissen JGM, Bajpai S, Hussain ST, Kumar K (2004) Eocene evolution of whale hearing. Nature 430(7001), 776.

Nummela S, Thewissen JGM, Bajpai S, Hussain ST, Kumar K (2007) Sound transmission in archaic and modern whales: anatomical adaptations for underwater hearing. Anat Rec 290(6), 716-733.

Nummela S, Thewissen JGM (2008) The Physics of Sound in Air and Water. In: Thewissen JGM, Nummela S (Eds.) Sensory Evolution on the Threshold: Adaptations in Secondarily Aquatic Vertebrates, pp. 175-182. University of California Press.

O'Leary MA, Gatesy J (2007) Impact of increased character sampling on the phylogeny of Cetartiodactyla (Mammalia): combined analysis including fossils. Cladistics 23, 1-46.

Orliac MJ, Araújo R, Lihoreau F (2017) The petrosal and bony labyrinth of Diplobune minor, an enigmatic Artiodactyla from the Oligocene of Western Europe. J Morphol 278, 11681184.

Orliac MJ, Billet G (2016) Fallen in a dead ear: intralabyrinthine preservation of stapes in fossil artiodactyls. Paleovertebrata 40(1), 1-10.

Peake WT, Rosowski JJ (1991) Impedance matching, optimum velocity, and ideal middle ears. Hear Res 53, 1-6.

Puria S, Steele C (2010). Tympanic-membrane and malleus-incus-complex co-adaptations for high-frequency hearing in mammals. Hear res 263(1-2), 183-190.

R Core Team (2018) R: a language and environment for statistical computing. Version 3.4.4. $R$ foundation for statistical computing, Vienna, Austria. https://www.r-project.org/

Remy JA, Crochet JY, Sigé B, Sudre J, Bonis L, Vianey-Liaud M, Godinot M, Hartenberger, JL, Lange-Badré B, Comte B (1987) Biochronologie des phosphorites du Quercy: mise à jour des listes fauniques et nouveaux gisements de mammifères fossiles. Münchner Geowiss Abh 10(A), 169-188. 
Rohlf FJ (1990) Rotational fit (Procrustes) Methods. In: Rohlf FJ, Bookstein FL (Eds.) Proceedings of the Michigan Morphometric Workshop, pp. 227-236. University of Michigan Museum of Zoology Special Publication 2.

Romer AS (1966) Vertebrate paleontology. Third Edition. Chicago: University of Chicago Press, 468 p.

Schmelzle T, Nummela S, Sánchez-Villagra MR (2005) Phylogenetic transformations of the ear ossicles in marsupial mammals, with special reference to diprotodontians: a character analysis. Ann Carnegie Mus 74(3), 189-200.

Schubert ED (1978) History of research on hearing. In: Carterette EC, Friedman MP (Eds.) Hearing, Handbook of Perception Volume IV, pp. 41-80. New York, San Francisco, London: Academic Press.

Simpson GG (1959) Mesozoic Mammals and the Polyphyletic Origin of Mammals. Evolution 13(3), 405-414.

Solntseva G (2013) Adaptive features of the middle ear of mammal in ontogeny. Act Zool Bulgarica 65, 101-116.

Stoessel A, Gunz P, David R, Spoor F (2016) Comparative anatomy of the middle ear ossicles of extant hominids-Introducing a geometric morphometric protocol. J hum evol 91, 1-25.

Sudre J, Legendre S (1992) Ungulates from Paleogene of Western Europe: relationships between their evolution and environmental changes during that period. In: Ongulés/Ungulates, pp 15-25. Toulouse: SFEPM-IRGM.

Theodor JM (2010) Micro-Computed Tomographic Scanning of the Ear Region of Cainotherium: Character Analysis and Implications. J Vert Paleontol 30(1), 236-243.

Thewissen JGM (1994) Phylogenetic aspects of Cetacean origins: A morphological perspective. J Mamm Evol 2, 157-184.

Thewissen JGM, Cooper LN, Clementz MT, Bajpai S, Tiwari BN (2007) Whales originated from aquatic artiodactyls in the Eocene epoch of India. Nature 450, 1190-1195.

Thewissen JGM, Hussain ST (1993) Origin of underwater hearing in whales. Nature 361(6411), 444.

Visualization Sciences Group - an FEI Company (2018) Avizo: 3D Analysis Software for Scientific and Industrial Data.

Webb SD, Taylor BE (1980) The phylogeny of hornless ruminants and a description of the cranium of Archaeomeryx. Bull Am Museum Nat Hist 167, 117-158.

Weppe R (2018) Cainotheriidés (Mammalia, Artiodactyla) et Grande Coupure : nouveau matériel des phosphorites du Quercy. MSc thesis, Université de Montpellier. 
660

661

662

663

664

665

666

667

668

669

670

671

672

673

674

675

676

677

678

679

680

681

682

683

Weppe R, Blondel C, Vianey-Liaud M, Escarguel G, Pélissié T, Antoine P-O, Orliac MJ (2019) Cainotheriidae (Mammalia, Artiodactyla) from Dams (Quercy, SW France): phylogenetic relationships and evolution around the Eocene-Oligocene transition (MP19MP21). J Syst Palaeontol 1-32.

Wever EG, Lawrence M (1954) Physiological Acoustics. London: Princeton University Press.

Wible JR, Spaulding M (2012) A reexamination of the Carnivora malleus (Mammalia, Placentalia). PLoS ONE 7, e50485.

Wilkie HC (1925) The Ossicula Auditûs of the Sheep (Ovis aries). J Comp Pathol Ther 38, 298-301.

Wilkie HC (1936) The Auditory Organ of the Ox (Bos taurus ). Proc Zool Soc London 106, 985-1009.

Willi UB, Bronner GN, Narins PM (2006). Ossicular differentiation of airborne and seismic stimuli in the Cape golden mole (Chrysochloris asiatica). J. Comp. Physiol. A, 192(3), 267-277.

Yezerinac SM, Lougheed SC, Handford P (1992) Measurement error and morphometric studies: statistical power and observer experience. Syst Biol 41(4), 471-482.

Figure captions

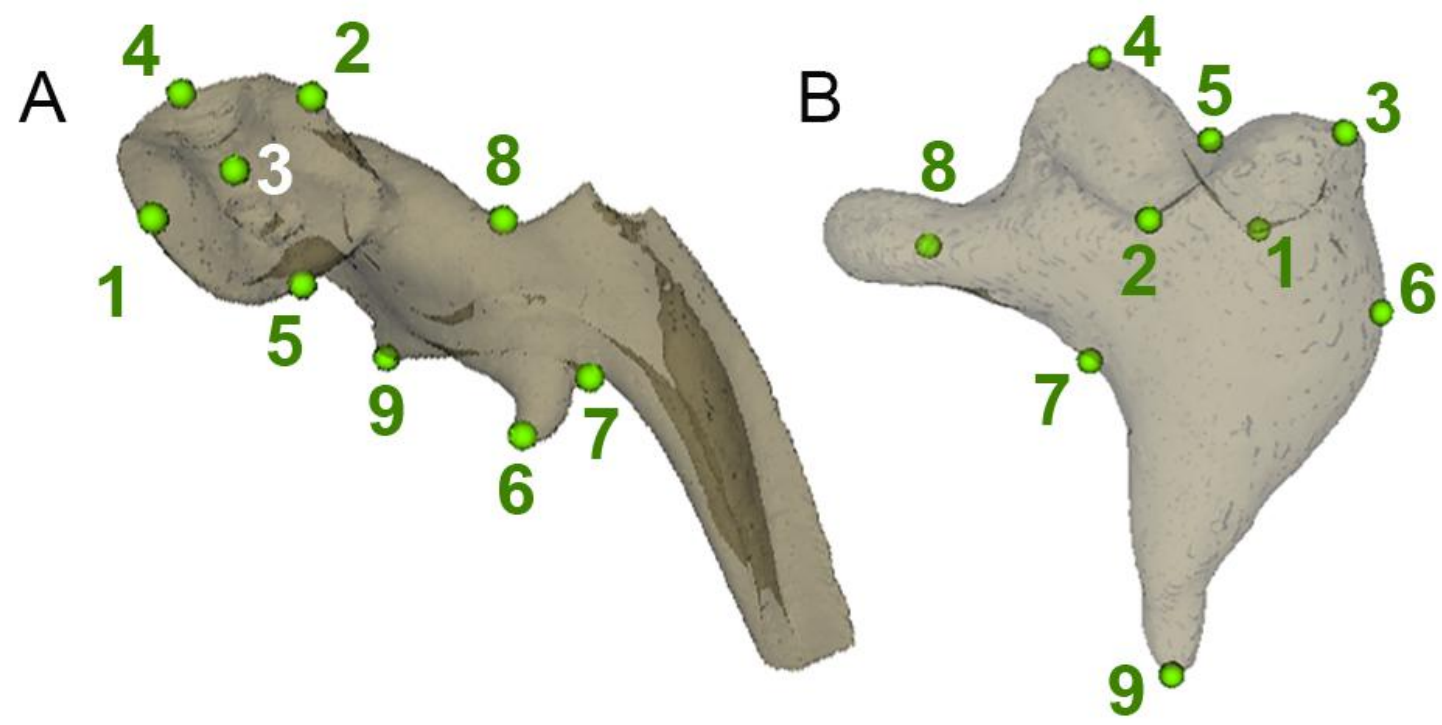

Figure 1. Position of landmarks used in the Generalized partial Procrustes analysis (pGPA) and principal component analysis (PCA) on the malleus (A) and the incus (B) of late Eocene and early Oligocene Cainotheriidae from Dams localities (DAM1 and DAM3, Phosphorites of Quercy, SW France). 

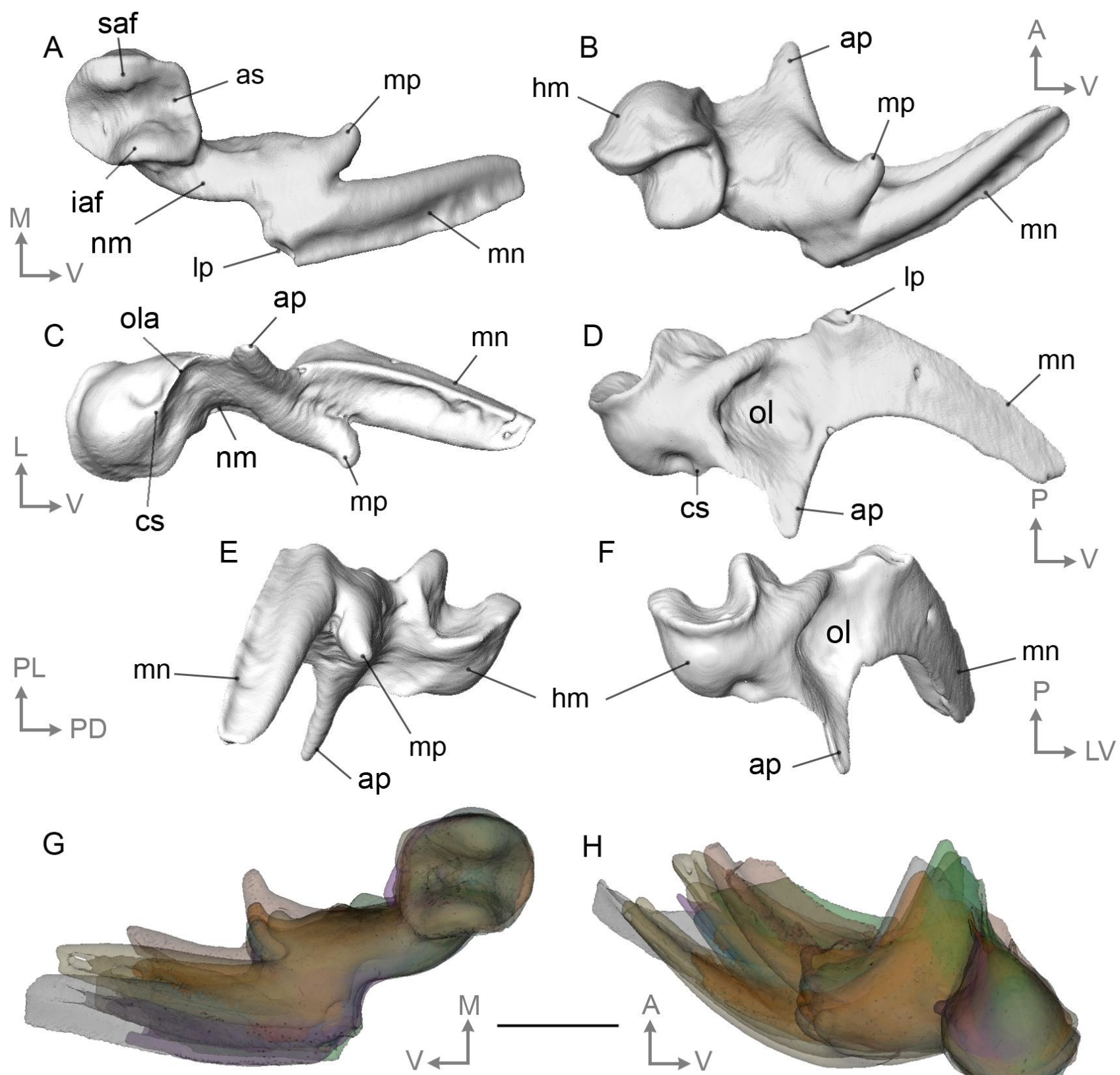

Figure 2. Left cainotheriid malleus from Dams DAM1 (DAM1 330) in (A) posterior, (B) medial, (C) anterior, (D) lateral, (E) medioventral, and (F) dorsolateral views. G-H, Illustration of morphological variability as observed in $(\mathrm{G})$ posterior and $(\mathrm{H})$ dorsomedial views of a right malleus). Abbreviations: ap, anterior process; as, articular surface; cs, capitular spine; hm, head of malleus; iaf, inferior articular facet; lp, lateral process; mn, manubrium; mp, muscular process; nm, neck of malleus; ol, osseous lamina; ola, outer lamella; saf, superior articular facet. Orientations: A, anterior; D, dorsal; L, lateral; M, medial; $\mathrm{P}$, posterior; $\mathrm{V}$, ventral. Scale bar $=1 \mathrm{~mm}$. 


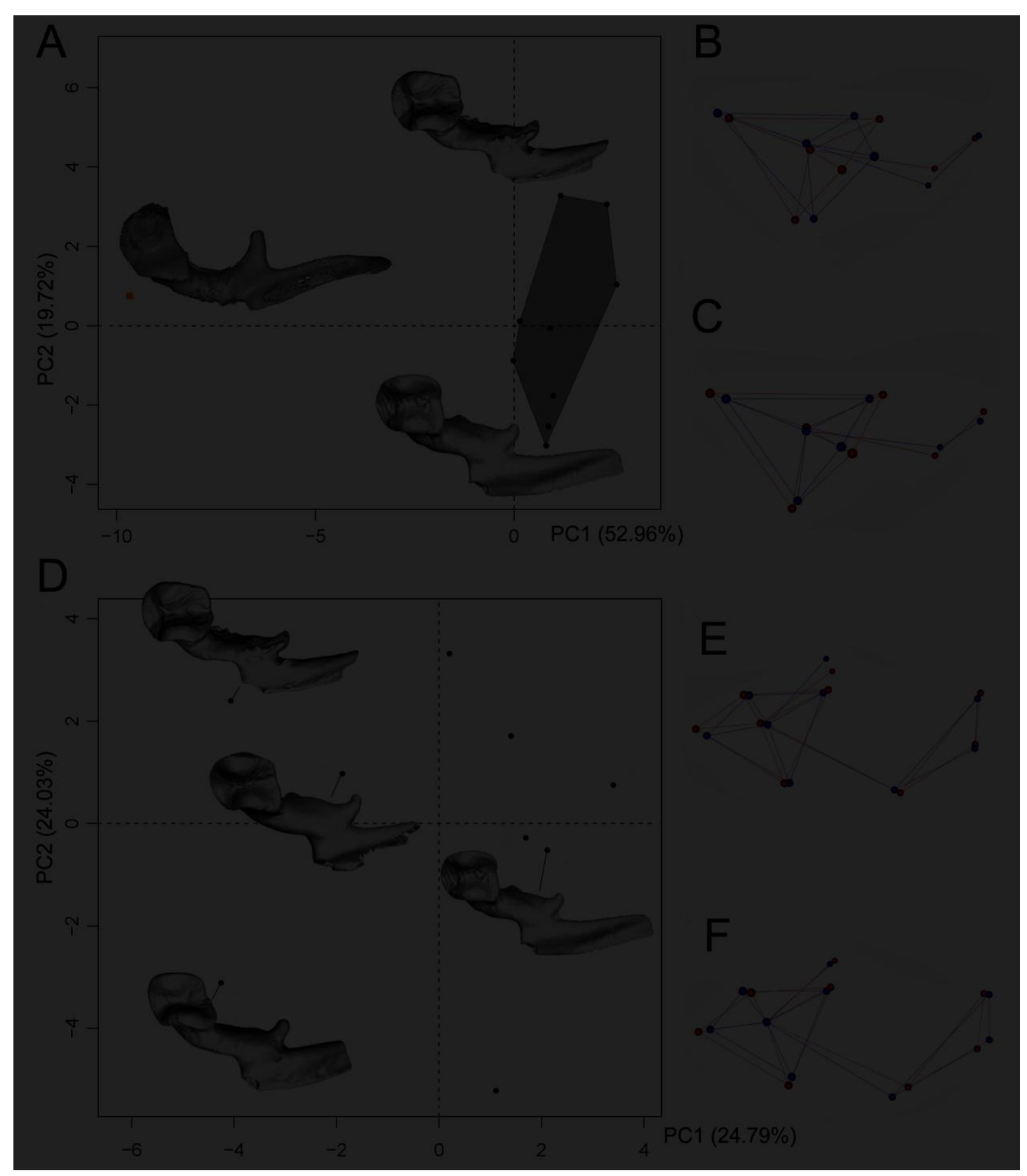

Figure 3. PCAs on Procrustes coordinates illustrating morphological variability of the cainotheriid malleus from DAM1 (late Eocene, Phosphorites of Quercy, SW France). (A) Inter- and intraspecific variation of the shape of the malleus based on 7 landmarks; projection of specimens from DAM1 (in black) and Pech Desse (in orange) on the first factorial plane; (B-C; E-F) Patterns of variation along PCs with maximal values in red and minimal in blue; (B) shape variation on PC1 of (A); (C) shape variation on PC2 of (A); (D) Intraspecific variation of the shape of the malleus based on 9 landmarks; projection of specimens from DAM1 on the first two PCs; (E) shape variation on PC1 of (D); (F) shape variation on PC2 of (D). See text for more details. 


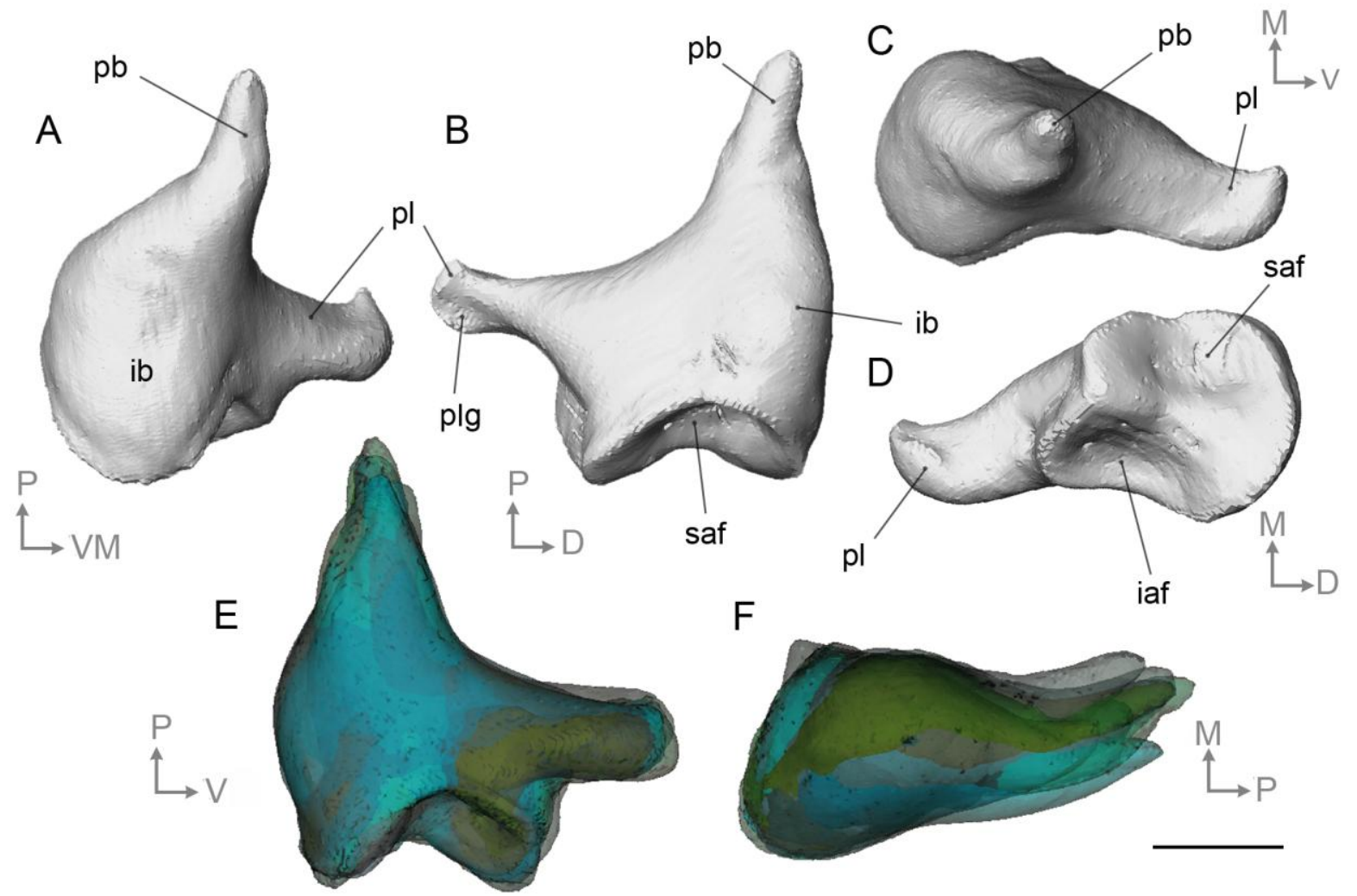

Figure 4. Left cainotheriid incus from Dams DAM1 (DAM 1 307) in (A) dorsomedial, (B) lateral, (C) posterior, (D) anterior, views. E-F, Illustration of morphological variability range as observed in (E) lateral and (F) dorsal views. Abbreviations: iaf, inferior articular facet; ib, incus bulge; pb, processus brevis; pl, processus longum; plg, processus longum groove; saf, superior articular facet. Orientations: A, anterior; D, dorsal; L, lateral; M, medial; P, posterior; $\mathrm{V}$, ventral. Scale bar $=0.5 \mathrm{~mm}$. 


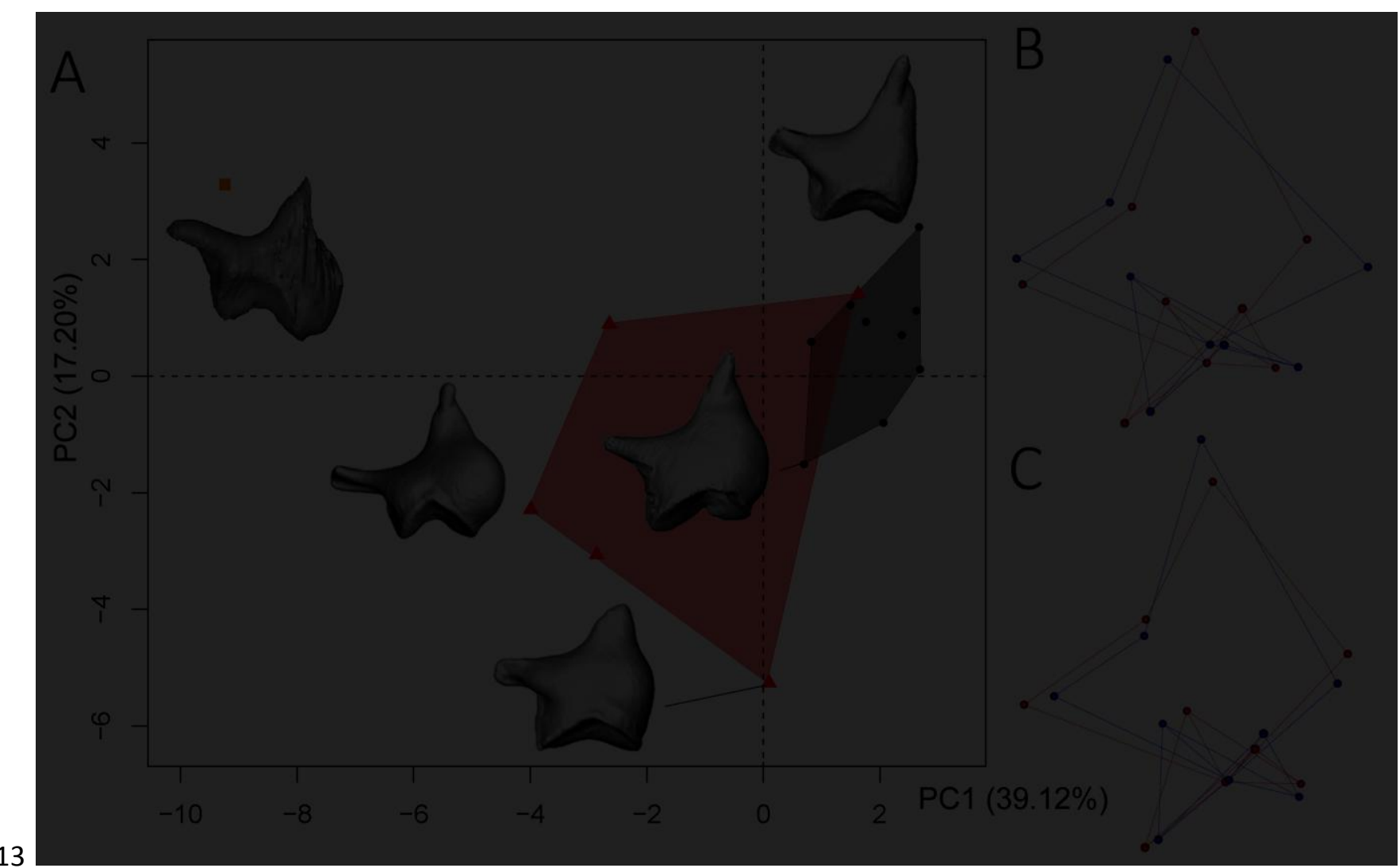

714 Figure 5. PCA on Procrustes coordinates illustrating morphological variability of the 715 cainotheriid incus from the localities of DAM1 (grey surface; late Eocene), DAM3 (pink 716 surface; early Oligocene) and Pech Desse (orange square; late Oligocene). (A) Projection of 717 individuals on the first factorial plane; (B-C) Patterns of variation along PC1 (B) and PC2 (C) 718 with maximal values in red and minimal in blue. 


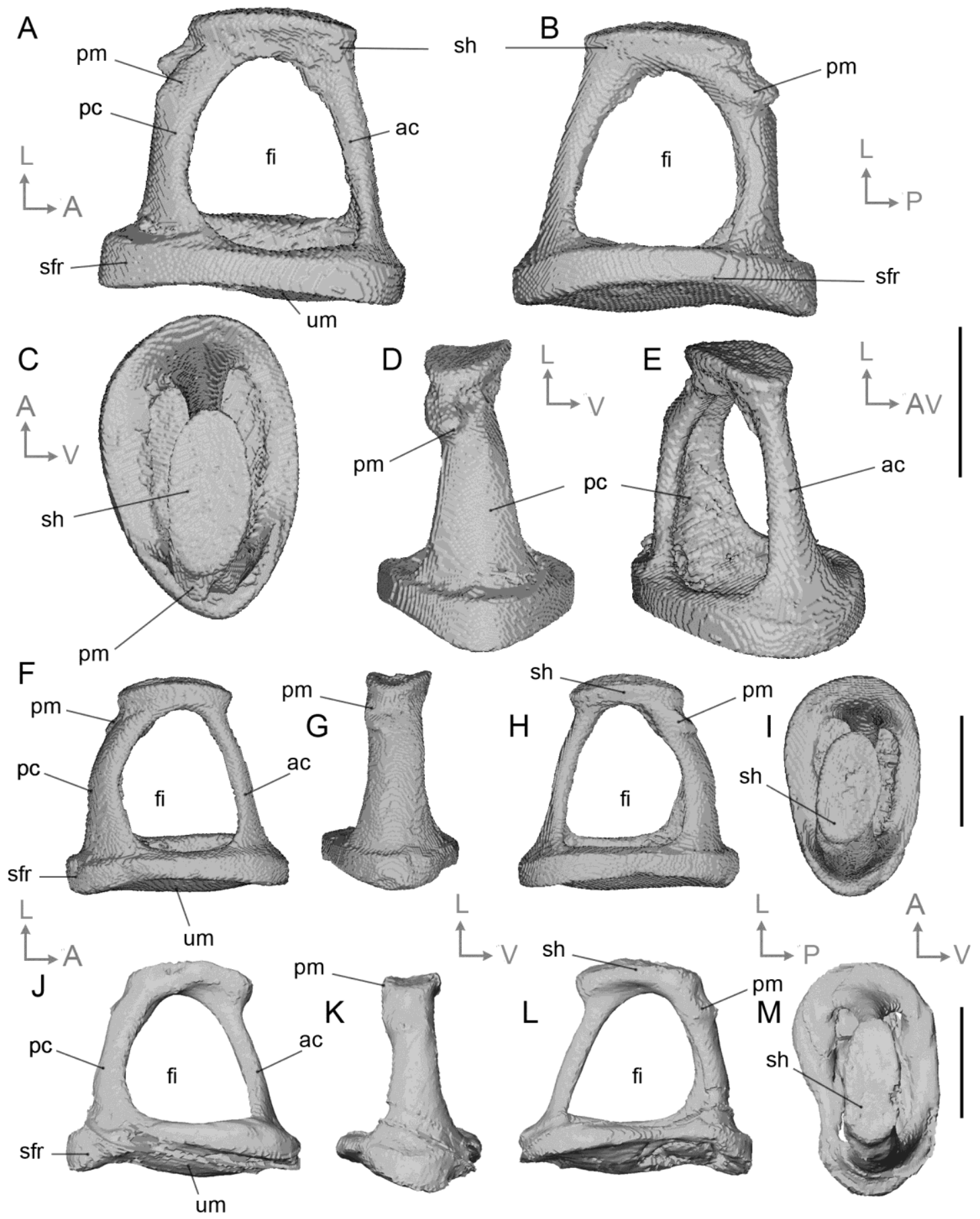

Figure 6. Right stapes of Paleogene Cainotheriidae from the Phosphorites of Quercy, SW France. (A-I) Paroxacron valdense from DAM1, late Eocene (A-E, DAM 1 316,) (F-I. DAM 1317 ) - A, ventral view; $B$, dorsal view; $C$, lateral view; $D$, posterior view; $E$, antero dorsal view. DAM 1317 (F-I) - F, ventral view; G, posterior view; H, dorsal view; I, lateral view. (J-M) Cainotheriidae indet. from DAM3, early Oligocene (DAM 3 13) J, ventral view; K, posterior view; L, dorsal view; M, lateral view; Abbreviations: ac, anterior crus; fi, foramen intercrurale; pc, posterior crus; pm, processus muscularis; sfr, stapedial footplate rim; sh, stapes head; um, umbo. Orientations: A, anterior; D, dorsal; L, lateral; M, medial; P, posterior; $\mathrm{V}$, ventral. Scale bars $=0.5 \mathrm{~mm}$. 

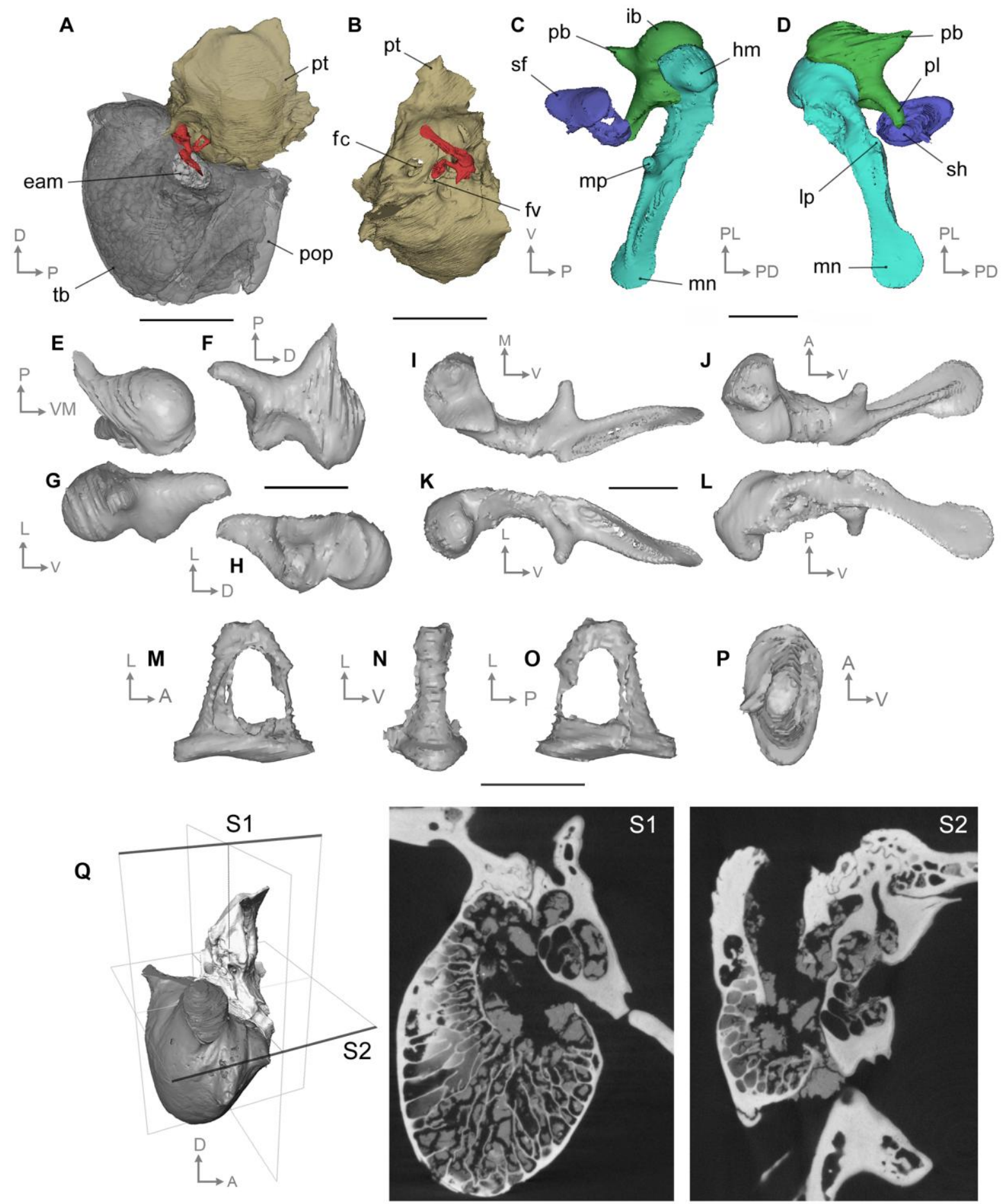

Figure 7. 3D reconstruction of the middle ear of Caenomeryx cf. procommunis from Pech Desse, late Oligocene, Phosphorites of Quercy, SW France (UM PDS 3353). A-B: Left middle ear with in-situ ossicles; C-D: virtually reassembled composite left ossicle chain in ventral (C) and dorsal (D) views; E-H: incus; I-L, malleus; M-P, stapes; Q, Petro-tympanic complex of UM PDS 3353 showing orthogonal slices (S1 and S2) at putative location of the processus internus prearticularis (pipa). Abbreviations: eam, external auditory meatus; fc, fenestra cochleae; fv, fenestra vestibuli; hm, head of malleus; ib, incus bulge; lp, lateral process of malleus; mn, manubrium; mp, muscular process of malleus; pb, processus brevis of the incus; pl, processus longum of the incus; pop, paroccipital process; pt, petrosal bone; sf, 
739 stapedial footplate; sh, stapes head; tb, tympanic bulla. Orientations: A, anterior; D, dorsal; L,

740 lateral; M, medial; P, posterior; V, ventral. Scale bars, A-B $=5 \mathrm{~mm} ; \mathrm{C}-\mathrm{P}=1 \mathrm{~mm}$. 